\title{
Adverbs of Action and Logical Form
}

\author{
KIRK LUDWIG
}

Adverbs modify verbs ('He cut the roast carefully'), adjectives ('A very tall man sat down in front of me'), other adverbs ('He cut the roast very carefully'), and sentences ('Fortunately, he cut the roast with a knife'). This chapter focuses on adverbial modification of verbs, and specifically action verbs, that is, verbs that express agency - though many of the lessons extend to sentences with event verbs generally. Adverbs and adverbial phrases are traditionally classified under the headings of manner ('carefully'), place ('in the kitchen'), time ('at midnight'), frequency ('often'), and degree ('very'). The problem of adverbials lies in understanding their systematic contribution to the truth conditions of the sentences in which they appear. The solution sheds light on the logical form of action sentences with and without adverbials.

An account of the logical form of a sentence aims to make clear the role of its semantically primitive expressions in fixing the sentence's interpretive truth conditions and, in so doing, to account for all of the entailment relations the sentence stands in toward other sentences in virtue of its logico-semantic form. This is typically done by providing a regimented paraphrase of the sentence that makes clearer the logico-semantic contribution of each expression. For example, the logical form of 'The red ball is under the bed' may be represented as '[The $x: x$ is red and $x$ is a ball][the $y: y$ is a bed]( $x$ is under $y)$.' Thus, the definite descriptions are represented as functioning as restricted quantifiers, and the adjective 'red' is represented as contributing a predicate conjunct to the nominal restriction on the variable in the first definite description.

[1] entails each of the sentences obtained from it by deleting any of the adverbials in brackets or any combination of them; and each of those sentences in turn entails each sentence got from it by deleting any remaining adverbials or combination of them - though not vice versa. This is sometimes called 'modifier drop entailment.' [1] and [2] together entail [3], though [1] alone does not. [3] in turn entails [1].

[1] He cut the roast [carefully] [with a knife] [in his dressing gown] [at midnight] [in the kitchen].

[2] He cut the roast only once.

[3] His cutting of the roast was done carefully, with a knife, in his dressing gown, at midnight, in the kitchen. 
These are formal entailments because we recognize their validity in virtue of the pattern of categories of terms in them. That we recognize their validity in virtue of the pattern of categories of terms in them rules out taking each of the sentences derived from [1] by deleting some combination of the adverbials as involving a verb with a different number of argument places, for then the entailments would depend on the meaning of the verb and not on the form of the sentence. In addition, the suggestion that we take each sentence derived from [1] by deleting some combination of adverbials as involving a verb with a different number of argument places would require an infinity of verbs of differing polyadicity, as there is no end to the number of adverbials one can add to a sentence (Kenney 1963, ch. 7). These would plausibly have to be learned independently, since verbs with a distinct number of argument places differ in meaning. The suggestion entails then that to master a natural language like English one has to learn an infinite number of verbs independently. It therefore violates a widely accepted constraint on meaning theories for natural languages, namely, that, on pain of their not being learnable by finite beings like us, natural languages should be represented as having a finite number of semantical primitives (Davidson 1966).

The standard solution to the problem of the semantic contribution of adverbs of action is the event analysis - the locus classicus is Davidson's paper "The logical form of action sentences" (1967), though he is anticipated by Ramsey (1927: 37; for some dissenting views, which champion an operator approach, see Clark 1970; Montague 1974; Rennie 1971; Schwartz 1975; Fulton 1979; Cresswell 1979; Clark 1986). The event analysis treats action verbs as introducing an implicit or hidden quantifier over events, and adverbials as introducing predicates of them. This is strongly suggested by the fact that [3], which contains a description of an event, entails [1] and is entailed by [1] in conjunction with [2], as well as by the fact that adverbs are typically derived from adjectives, which function in logical form as predicates. (In some languages, for example in Dutch and in German, adjectives and adverbs have the same form.) On Davidson's original proposal, [1] would be analyzed as in [1'], where ' $e$ ' is a variable for events (we treat 'careful' as relating an agent to an event, since no event is careful considered in itself).

[1'] $(\exists e)(\operatorname{cut}(e$, he, the roast) and $\operatorname{careful}(e$, he $)$ and with $(e$, a knife $)$ and in $(e$, his dressing gown) and at (e, midnight) and in( $e$, the kitchen $)$.

This analysis captures all the entailments from [1] to any sentence derived from it by deleting one or more of the adverbials. [1'] represents these entailments as a matter of conjunction elimination in the scope of an existential quantifier. This analysis also explains why [3] entails [1], and [1] and [2] together entail [3], whose analysis can be represented as in [3'].

[3'] [The $e$ : $\operatorname{cutting}(e$, he, the roast $)](\operatorname{careful}(e$, he $)$ and with $(e$, a knife $)$ and in $(e$, his dressing gown) and at (e, midnight) and in(e, the kitchen)).

The two-place predicates relating the event to a 'participant' are called case or thematic

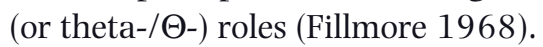


In a comment on Davidson's 1967 paper, Hector-Neri Castañeda (1967) suggested separating out, in addition, the case roles of the subject and object terms and treating them as separate relational predicates of the event, in order to capture entailments such as those between [4] and [5] and [4] and [6] (for discussion and development, see Bennett 1988; Carlson 1984; Parsons 1980, 1985, 1990; Dowty 1989; Schein 1993). The subject is the agent of the event and the object is its patient, what the agent acts on. When we separate out these case roles, we must take into account that action sentences like [1] and [4] imply that the subject is the sole relevant agent of the event expressed. We will use 'agent $(e, x)$ ' to express the relation of $x$ 's being an agent of $x$ and write 'the-agent $(e, x)$ ' to express 'agent $(e, x)$ and (only $y=x)(\operatorname{agent}(e, y)$.' We would then analyze [4] as in [4'], where 'patient $(e, x)$ ' expresses a relation between the event and its object, i.e., being the object in which the event is a change. [5] and [6] would be analyzed as in [5'] and [6'], which show how [5] and [6] follow from [4] on the proposed analysis.

[4] He flew the spaceship.

[4'] $(\exists e)($ the-agent $(e$, he) and flying $(e)$ and patient $(e$, the spaceship)).

[5] He did something.

[5'] $(\exists e)($ the-agent $(e$, he $))$.

[6] The spaceship flew.

[6'] $(\exists e)($ flying $(e)$ and patient $(e$, the spaceship)).

On this suggestion, we would analyze [1] as in [1"].

[1"] $(\exists e)($ the-agent $(e$, he $)$ and $\operatorname{cutting}(e)$ and patient $(e$, the roast) and careful $(e$, he $)$ and with(e, a knife) and in(e, his dressing gown) and at (e, midnight) and in(e, the kitchen)).

On the analysis represented in [1"], [1] entails each sentence derived from it by deleting any combination of adverbials; and together with [2] it entails [3], and likewise [3] entails [1], with the nominal restriction in the noun phrase reinterpreted as 'the$\operatorname{agent}(e$, he) and patient $(e$, the roast) and cutting $(e)$.'

A remark is in order about the use of 'cutting $(e)$ ' in [ 1 "] to express the event type brought about by the agent that could have come about independently. Not all transitive action verbs in English have an intransitive counterpart in which the object of the first appears as the subject of the second. Verbs that do, like 'fly,' 'melt,' 'break,' 'combine,' 'move,' are called alternating ambitransitive verbs; the intransitive forms, which (unlike the passive forms, for example, 'was melted') strip out the implication of agency, are anticausative or inchoative verbs (the argument structure alternation is often called 'inchoative/causative' alternation). Generalizing the treatment of [4] to action verbs generally commits us to a predicate in logical form which may not have an explicit English counterpart. In favor of this is that [1] like [4] entails [5], an entailment captured by [1"]. For action sentences like [1], whose main verb is not an alternating ambitransitive, we use the gerund to express the consequent event type in logical form.

The analysis so far has ignored tense. Davidson among others suggested that quantification over events suffices to handle tense, the utterance of the sentence serving as 
a reference point for the event time. Thus 'He cut the roast' may be rendered as in [7], where ' $u$ ' is an indexical that refers, in the context of an utterance of [7], to that utterance of [7] itself, and '<' means 'is earlier than.'

[7] $[\exists e: e<u]($ the-agent $(e$, he $)$ and cutting $(e)$ and patient $(e$, the roast $))$.

What I say in asserting 'He cut the roast,' though, could have been true in a world in which I did not utter that sentence: but not if it involves a reference to my utterance of it, as the proposed analysis requires. The natural alternative is to treat tense as introducing a quantifier over times, so that 'He cut the roast' may be rendered as in [7'], where ' $t$ ' ' is an indexical that refers to the time of the utterance (roughly, 'now').

$\left[7^{\prime}\right] \quad\left[\exists t: t<t^{*}\right](\exists e)($ the-agent $(e, t$, he $)$ and cutting $(e)$ and patient $(e$, the roast $))$.

We interpret 'the-agent $(e, t, x)$ ' here as 'agent $(e, t, x)$ and (only $y=x)\left(\exists \mathrm{t}^{\prime}\right)\left(\operatorname{agent}\left(e, t^{\prime}\right.\right.$, $y)$.' We include a separate quantifier over time intervals for the clause that secures uniqueness because, as we will see, this time indexes to the primitive action of the agent, and we want to exclude contributions of the relevant sort by any other agent at any other time. As explained below, the need to discover more structure in the agency relation than we have so far motivates including the temporal variable in the agency predicate but not in the event predicate. With a temporal variable to modify as well as an event variable, we can revisit [ $\left.1^{\prime \prime}\right]$ to see whether it makes better sense to treat some of the adverbials as modifying the time rather than the event. Plausibly the temporal adverbial modifies the time; 'in his dressing gown' is more naturally treated as a relation between time, agent, and dressing gown, as in [1"'].

$\left[1^{\prime \prime \prime}\right] \quad\left[\exists t: t<t^{*}\right](\exists e)($ the-agent $(e, t$, he) and cutting $(e)$ and patient $(e$, the roast) and $\operatorname{careful}(e, \mathrm{he})$ and with( $(e$, a knife $)$ and in( $t$, he, his dressing gown) and at $(t$, midnight) and in(e, the kitchen)).

The analysis in [ $\left.1^{\prime \prime \prime}\right]$ creates a problem in connection with the view that the same action may be redescribed in terms of various of its effects, which was first noted in an unpublished paper by John Wallace (reported in Parsons 1980). Suppose that I move my finger, flip a switch, turn on the light, illuminate the room, and alert a prowler. According to Anscombe (1957), I have done one thing which I have described in five ways (the example is from Davidson 1963, who follows Anscombe). What I did was move my finger. That is the only thing I did but not by doing anything else; it was my only primitive action. The other action sentences redescribe my primitive action in terms of its consequences. Suppose we identify an agent's actions with the events which render action sentences about him true. Consider [8] and [9] (the example is from Pietroski 2000), together with analyses patterned after $\left[1^{\prime \prime \prime}\right]$ in $\left[8^{\prime}\right]$ and $\left[9^{\prime}\right]$, but suppressing tense for the moment.

[8] Booth pulled the trigger with his finger.

[8'] $(\exists e)($ the-agent $(e$, Booth $)$ and pulling $(e)$ and patient $(e$, the trigger $)$ and with $(e$, his finger)). 
[8"] the-agent( $\varepsilon$, Booth) and pulling $(\varepsilon)$ and patient( $\varepsilon$, the trigger) and with( $\varepsilon$, his finger).

[9] Booth shot Lincoln with a gun.

$\left[9^{\prime}\right] \quad(\exists e)($ the-agent $(e$, Booth $)$ and $\operatorname{shooting}(e)$ and patient $(e, \operatorname{Lincoln})$ and with $(e$, a gun)).

[9"] the-agent( $\varepsilon$, Booth) and shooting $(\varepsilon)$ and patient( $\varepsilon$, Lincoln) and with( $\varepsilon$, a gun).

Suppose [8] and [9] are about Booth on the night of his assassination of Lincoln. He did one thing that made both of these sentences true. Let that be designated by ' $\varepsilon$ '. Then we have [ $\left.8^{\prime \prime}\right]$ and [9"], if we assume that the variable ' $e$ ' in [ $\left.8^{\prime}\right]$ and [9'] takes the agent's actions as values. From [8"] and [9"] we can infer [10] and [11], and in turn [10'] and $\left[11^{\prime}\right]$, which are false.

[10] the-agent( $\varepsilon$, Booth) and pulling $(\varepsilon)$ and patient( $\varepsilon$, the trigger $)$ and with $(\varepsilon, a$ gun).

[10'] Booth pulled the trigger with a gun.

[11] the-agent $(\varepsilon$, Booth) and $\operatorname{shooting}(\varepsilon)$ and patient( $\varepsilon$, Lincoln) and with $(\varepsilon$, his finger).

[11'] Booth shot Lincoln with his finger.

Davidson (1985) proposed resolving this problem by introducing a second quantifier over events, which would bind an event variable that represented a primitive action of the agent, which bears an appropriate relation to the consequent event (see also Lombard 1985; Vendler 1984). We can represent this in [9"'], now taking into account tense (we use 'agent' in the sense of 'primitive agent of'; 'the-(agent $(f, t, x)$ and $\operatorname{by}(f, e))^{\prime}$ abbreviates 'agent $(f, t, x)$ and by $(f, e)$ and $($ only $y=x)\left(\exists t^{\prime}\right)\left(\exists f^{\prime}\right)\left(\operatorname{agent}\left(f^{\prime}, t^{\prime}, y\right)\right.$ and $\left.\operatorname{by}\left(f^{\prime}, e\right)\right)^{\prime}$.

$\left[9^{\prime \prime \prime}\right] \quad\left[\exists t: t<t^{*}\right](\exists e)(\exists f)($ the- $(\operatorname{agent}(f, t$, Booth) and by $(f, e))$ and shooting $(e)$ and patient $(e, \operatorname{Lincoln})$ and $\operatorname{with}(e$, a gun $))$.

Now we can say that there is one thing Booth did, move his finger, and there were various consequences of it: the trigger pulling was done with his finger but the shooting, which is distinct, was done with a gun.

We represent the event time as that of the primitive action and not as that of the consequent event. Why? Suppose I put poison in someone's curry powder on Monday and I die on Tuesday. He makes curry on Saturday and dies that evening. When did I kill him? It is clear that what I did to kill him occurred on Monday, not on Saturday, that is, I killed him on Monday, though he did not die until Saturday. (In Hamlet, Laertes says, "I am justly kill'd with mine own treachery" while he still lives; for he has done something that will bring about his death.)

We represent the relation between primitive action and consequent event with 'by $(x, y)$.' This is a determinable. Different action verbs select different determinate relations. Thus we have so far underspecified the action verb's contribution. One can be an agent of an event in a variety of ways. One can be an agent of an event by being a primitive agent of it (as when I move my finger), by doing something that causes it 
(as when I break a window by throwing a brick at it), by doing something that contains it (as when I contract my forearm muscles by clenching my fist), or by doing something that partially or wholly constitutes it (as when I play chess by moving pieces intentionally in accordance with the rules). Many action verbs like 'kill' require that something we do contribute causally to a consequent event (in this case, a death) without being mediated (primarily) by another's agency. For example: If I hire an assassin to kill a rival and he does it, I cause the death of my rival, and so I am an agent of it, but I did not kill him. Similarly, if I direct someone to cut the roast, I cause it to be cut, but I do not cut it myself. These verbs require that we directly contribute to the consequent event. Thus, 'by $(f, e)$ ' in [9"'] should be subscripted to indicate the specific relation the action verb requires between the primitive action and the consequent event, for example, in the present case, to indicate directly contributing, we would write 'by $\mathrm{yc}_{\mathrm{DC}}(f, e)$ ' - mutatis mutandis for other action verbs and modes of agency.

Introducing a second quantifier helps with sentences such as [12], where 'by' relates two events, a striking of Lincoln by a projectile and Lincoln's death, as illustrated in $\left[12^{\prime}\right]$.

[12] Booth killed Lincoln by shooting him.

[12'] $\left[\exists t: t<t^{*}\right](\exists e)(\exists f)\left(\right.$ the-(agent $\left(f, t\right.$, Booth) and $\left.\operatorname{by}_{\mathrm{DC}}(f, e)\right)$ and $\operatorname{death}(e)$ and patient $(e, \operatorname{Lincoln})$ and $\left(\exists e^{\prime}\right)\left(\operatorname{by}_{\mathrm{DC}}\left(f, e^{\prime}\right)\right.$ and $\operatorname{shooting}\left(e^{\prime}\right)$ and patient $\left(e^{\prime}\right.$, Lincoln $)$ and by $\left.\left.\left(e^{\prime}, e\right)\right)\right)$.

In light of the second quantifier, we may also revisit the role of 'carefully' in [1], which is more plausibly treated as relating agents to primitive actions rather than consequent events.

From the standpoint of the event analysis, someone's actions must either be the events of which she is a primitive agent or both her primitive actions and the things that they bring about. Once we are clear about the underlying structure of agency, however, it is obvious that what we say reflects a choice about word use rather than a dispute about what goes on when we act. So-called negative actions - remaining silent, for example - which seem to present a problem for the analysis, may be brought into the fold by treating sentences attributing them as introducing a state rather than an event quantifier.

Adverbs, like 'slowly,' which have comparative and superlative forms ('more slowly,' 'slowest'), require separate treatment. If we analyze [13] as in [13'], and the subject's crossing of the Channel was her swimming of the Channel, then we can infer [14].

[13] She crossed the Channel slowly.

[13'] $\left[\exists t: t<t^{*}\right](\exists e)(\exists f)\left(\right.$ the- $\left(\operatorname{agent}\left(f\right.\right.$, $t$, she) and by $\left.\operatorname{by}_{\mathrm{DC}}(f, e)\right)$ and $\operatorname{crossing}(e)$ and patient $(e$, the Channel) and $\operatorname{slow}(e))$.

[14] She swam the Channel slowly.

But a slow crossing of the Channel may be a fast swimming of it. This shows that the contribution of 'slowly' is relative to a class determined by the verb it modifies. This is very clear for the superlative forms. The slowest crossing may be the fastest swimming, if the Channel has been swum only once. A crossing is slowest if it is slower than all 
other Channel crossings; a crossing is slow if it is slower than most crossings. Thus the analysis of [13] should yield [13"].

[13"] $\left[\exists t: t<t^{*}\right](\exists e)(\exists f)\left(\right.$ the-(agent $\left(f, t\right.$, she) and $\left.\operatorname{by}_{\mathrm{DC}}(f, e)\right)$ and $\operatorname{crossing}(e)$ and patient $\left(e\right.$, the Channel) and [most $e^{\prime}: e^{\prime}$ is a Channel crossing](e is slower than $\left.e^{\prime}\right)$ )

Adverbs of action expressing attitudes toward what is done, such as 'intentionally,' 'deliberately,' 'willingly,' 'reluctantly,' and the like, are of special interest. 'Intentionally,' for example, creates a partially intensional context. [15] entails [16]; and one can intersubstitute in the subject position on the basis of sameness of reference salva veritate (without risking change of truth value). But one cannot intersubstitute salva veritate in the object position, given sameness of reference or denotation, nor can one replace salva veritate the main verb with another verb that would, if 'intentionally' were deleted, otherwise yield a true sentence. Even if the roast is the king's venison, one cannot infer, from his cutting the roast intentionally, that he cut the king's venison intentionally. Similarly, even if in cutting the roast he offended the king, one cannot infer, from his cutting the roast intentionally, that he offended the king intentionally.

[15] He cut the roast intentionally.

[16] He cut the roast.

This has suggested to some that 'intentionally' is a sentential adverb, which, like 'allegedly' or 'fortunately,' modifies the whole sentence and is properly treated as a sentential operator, as in [15'].

\section{[15'] It was intentional of him that he cut the roast.}

However, this hardly makes clear the logical form of [15]. Why does it follow from this that he cut the roast? The adverb 'intentionally' is derived from the adjective 'intentional,' which is derived from the noun 'intention,' which is derived from the verb 'intend.' Assume what is sometimes called 'the Simple View': that one successfully carries out an intention to cut the roast if and only if one cuts the roast intentionally. (Some philosophers deny the right to left direction - we shall return to this shortly.) This suggests that you cut the roast intentionally if and only if you cut the roast and did it with the intention of so doing, where the 'so' picks up the content of the first clause - that is, you cut the roast and did it with the intention that it be a cutting of the roast. The pronoun of cross-reference 'it' in the second clause clearly picks out the action introduced by the verb in the first. The intention, then, is directed at what the agent does when he acts. Putting this together, we have [15"].

[15"] $\left[\exists t: t<t^{*}\right](\exists e)(\exists f)\left(\right.$ the-(agent $\left(f, t\right.$, he) and $\left.\operatorname{by}_{\mathrm{DC}}(f, e)\right)$ and cutting $(e)$ and patient $(e$, the roast) and intends $(t$, he, that $(\exists e)($ the-(agent $(f, t$, he $)$ and $\left.\operatorname{by}_{\mathrm{DC}}(f, e)\right)$ and $\operatorname{cutting}(e)$ and patient $(e$, the roast $\left.\left.)\right)\right)$. 
The quantifier binding the variable ' $f$ ' for the agent's primitive action in the first clause also binds, in the content clause, the corresponding position in the agency relation; the quantifier that binds the temporal argument place in the agency relation in the first clause also binds the temporal argument position in 'intends' and in the agency relation in its content clause. 'Intentionally' is thus treated as introducing a predicate not of the consequence event but of the agent, his primitive action, and the time at which he performs it. This corresponds to the fact that to cut the roast (to do something, F) intentionally one must have an intention directed at what one is doing at the time as a cutting of the roast (as an F-ing). It is not enough that one have an intention directed generally toward an action of the type one is in fact performing. One may have such an intention, and it may even cause the thing intended, though one doesn't do it intentionally. I intend at $t$ to strike fear into my enemy by clenching my fist. This recalls to me my anger at him, which causes me to clench my fist, which strikes fear into him. Yet I do not strike fear into my enemy intentionally, because the intention to do so by clenching my fist was not directed at the fist clenching that struck fear into him. The rejection of the simple view can be easily incorporated into this picture by adding a disjunct within the last conjunct in [15"] which expresses what further attitudes toward the relevant content (foreseen and undesired, for example) license the adverb 'intentionally.' On this account, one performs an action intentionally (unintentionally) under a 'description,' for example, 'cutting the roast,' if and only if the last conjunct in $\left[15^{\prime \prime}\right]$ is made true (false) by the event.

How does the event analysis project to plural action sentences? [18] differs from [17] solely in the number of the pronoun in the subject position.

\section{[17] I insulted the host.}

[18] We insulted the host.

As the referent of the subject term in [17] is the agent of the event expressed, so it seems we should treat the referent of the subject term in [18] as the agent of the event expressed. This would commit us to saying that we as such (the group consisting of us) are the agent of the insulting. However, [18] is ambiguous between a distributive and a collective reading. On the distributive reading, it is made true, for example, by my insulting the host before dinner and your insulting him afterwards. On the collective reading, it would be made true, for example, by our deliberately talking in our host's presence as if he were not there. Here we do it together. The distributive reading requires that we interpret the subject position as involving, in logical form, a restricted quantifier over members of the group picked out by 'We,' as in [18'], which, with the event analysis of the matrix, gives us [18d] (expanding the abbreviation that secures uniqueness).

[18'] [Each $x$ of us] $(x$ insulted the host).

[18d] [Each $x$ of us] $\left[\exists t: t<t^{*}\right](\exists \boldsymbol{e})(\exists f)\left(\operatorname{agent}(f, t, x)\right.$ and $\operatorname{by}_{\mathrm{DC}}(f, e)$ and (only $\left.y=x\right)$ $\left(\exists t^{\prime}\right)\left(\exists f^{\prime}\right)\left(\operatorname{agent}\left(f^{\prime}, t^{\prime}, y\right)\right.$ and $\left.\operatorname{by}\left(f^{\prime}, e\right)\right)$ and insulting $(e)$ and patient $(e$, the host)).

[18c] $(\exists \boldsymbol{e})\left[\operatorname{Each} x\right.$ of us] $\left[\exists t: t<t^{*}\right](\exists f)\left(\operatorname{agent}(f, t, x)\right.$ and $\operatorname{by}_{\mathrm{DC}}(f, e)$ and (only $y: y$ is one of us) $\left(\exists t^{\prime}\right)\left(\exists f^{\prime}\right)\left(\operatorname{agent}\left(f^{\prime}, t^{\prime}, y\right)\right.$ and $\left.\operatorname{by}_{\mathrm{DC}}\left(f^{\prime}, e\right)\right)$ and insulting $(e)$ and patient(e, the host)). 


\section{KIRK LUDWIG}

The collective reading is now obtained simply by giving the event quantifier wide scope, as in [18c], and by making a corresponding adjustment to the requirement of uniqueness of agency, to ensure that only members of the group are among the relevant agents of the event. We do something together, then, when we (and only we) are all agents, in the relevant way, via our various individual actions, of a single event. The distributive/collective ambiguity of plural action sentences thus emerges as a scope ambiguity and we can see that plural action sentences do not commit us to group agents per se (for further discussion see Landman 2000; Lasersohn 1989, 1995; Ludwig 2007; Schein 1993, 2002; for discussion of a variety of advanced topics in event semantics see Higginbotham et al. 2000).

See also: ACTION THEORY AND ONTOLOGY (1); BASIC ACTIONS AND INDIVIDUATION (2); THE CAUSAL THEORY OF ACTION (5); COLLECTIVE ACTION (9); REFRAINING, OMITTING, AND NEGATIVE ACTS (7); AGENT CAUSATION (28); DAVIDSON (73); ANSCOMBE (74).

\section{References}

Anscombe, G. E. M. (1957). Intention. Oxford: Blackwell.

Bennett, J. (1988). Events and their Names. Oxford: Clarendon Press.

Carlson, G. (1984). Thematic roles and their role in semantic interpretation. Linguistics, 22, 259-279.

Casteñeda, H.-N. (1967). Comments on Donald Davidson's 'The logical form of action sentences.' In N. Rescher (ed.), The Logic of Decision and Action. Pittsburgh: University of Pittsburgh Press, $104-112$.

Clark, R. (1970). Concerning the logica of predicate modifiers. Nous 4, 311-335.

Clark, R. (1986). Predication and paronymous modifers. Notre Dame Journal of Formal Logic, 27, 376-392.

Cresswell, M. J. (1979). Interval semantics for some event expressions. In R. Bäuerle, U. Egli, and A. von Stechow (eds), Semantics from Different Points of View. Berlin: Springer-Verlag, 90-116.

Davidson, D. (1963). Actions, reasons, and causes. The Journal of Philosophy, 60, 685-699.

Davidson, D. (1966). Theories of meaning and learnable languages. In Y. Bar-Hillel (ed.), Proceedings of the 1964 International Congress for Logic, Methodology and Philosophy of Science. Amsterdam: North Holland Publishing Co., 383-394.

Davidson, D. (1967). The logical form of action sentences. In N. Rescher (ed.), The Logic of Decision and Action. Pittsburgh: University of Pittsburgh Press, 81-95.

Davidson, D. (1985). Adverbs of action. In B. Vermazen and M. Hintikka (eds), Essays On Davidson. Oxford: Clarendon Press, 230-241.

Dowty, D. R. (1989). On the semantic content of the notion of 'thematic role.' In G. Chierchia, B. H. Partee, and R. Turner (eds), Properties, Types and Meaning. Dordretcht: Kluwer Academic Publishers, 69-129.

Fillmore, C. J. (1968). The case for case. In E. Bach and R. T. Harms (eds), Universals in Linguistic Theory. New York: Holt, Rinehart, and Winston, 1-88.

Fulton, J. (1979). An intensional logic of predicates. Notre Dame Journal of Formal Logic, 34, 607-620.

Higginbotham, J., F. Pianesi, and A. C. Varzi, eds. (2000). Speaking of Events. New York: Oxford University Press. 
Kenney, A. (1963). Action, Emotion and Will. London: Routledge.

Landman, F. (2000). Events and Plurality: The Jerusalem Lectures. Dordretch: Kluwer Academic Publishers.

Lasersohn, P. (1989). On the readings of plural noun phrases. Linguistic Inquiry, 20, 130134.

Lasersohn, P. (1995). Plurality, Conjunction and Events. Dordretch: Kluwer Academic Publishers.

Lombard, L. (1985). How not to flip the prowler: Transitive verbs of action and the identity of actions. In E. Lepore and B. McLaughlin (eds), Actions and Events: Perspectives on the Philosophy of Donald Davidson. Oxford: Blackwell, 268-281.

Ludwig, K. (2007). Collective intentional behavior from the standpoint of semantics. Nous, 41, 355-393.

Montague, R. (1974). English as a formal language. In R. Thomason, ed., Formal Philosophy. New Haven: Yale University Press, 188-221.

Parsons, T. (1980). Modifiers and quantifiers in natural language. Canadian Journal of Philosophy, 6. 29-60.

Parsons, T. (1985). Underlying events in the logical analysis of English. In E. LePore and B. McLaughlin (eds), Actions and Events: Perspectives on the Philosophy of Donald Davidson. Oxford: Blackwell, 235-267.

Parsons, T. (1990). Events in the Semantics of English: A Study in Subatomic Semantics. Cambridge, MA: MIT Press.

Pietroski, P. M. (2000). Causing Actions. Oxford: Oxford University Press.

Ramsey, F. (1927). Facts and propositions. Proceedings of the Aristotelian Society (Suppl. 71927), $153-170$.

Rennie, M. K. (1971). Completeness of the logic of predicate modifiers. Logique et Analyse, 55, 627-643.

Schein, B. (1993). Plurals and Events. Cambridge, MA: MIT Press.

Schein, B. (2002). Events and the semantic content of thematic relations. In G. Preyer and G. Peter (eds), Logical Form and Language. Oxford: Clarendon Press, 261-344.

Schwartz, T. (1975). The logic of modifiers. Journal of Philosophical Logic, 4, 361-380.

Vendler, Z. (1984). Agency and causation. Midwest Studies in Philosophy: Causation and Causal Theories, 9, 371-384. 